University of Wollongong

Research Online

Faculty of Engineering and Information

Faculty of Engineering and Information

Sciences - Papers: Part A

Sciences

$1-1-2012$

\title{
Multifactor optimization of a Fuzzy-PID controller using genetic algorithm
}

Xiaofeng $\mathrm{He}$

Huazhong University of Science and Technology, xhe@uow.edu.au

Wei Chen

Huazhong University of Science and Technology

Bihai Zhu

Huazhong University of Science and Technology

Zhengyi Jiang

University of Wollongong, jiang@uow.edu.au

Christopher David Cook

University of Wollongong, chris_cook@uow.edu.au

Follow this and additional works at: https://ro.uow.edu.au/eispapers

Part of the Engineering Commons, and the Science and Technology Studies Commons

Research Online is the open access institutional repository for the University of Wollongong. For further information contact the UOW Library: research-pubs@uow.edu.au 


\title{
Multifactor optimization of a Fuzzy-PID controller using genetic algorithm
}

\begin{abstract}
The design of a Fuzzy-PID controller involves setting the fuzzy rules, membership functions and its associated scaling factors. How to obtain a better control result and how these scaling factors affect the controller's performance are still a challenge. In this paper, the automatic position control system of a Hille 100 experimental rolling mill was used as a research testbed. Based on the mathematical control model of the rolling mill, a Fuzzy-PID controller was developed, and the process of implementing global optimization considering all these factors simultaneously by using genetic algorithm is introduced in detail. Through simulation, the performance of the control system with multifactor optimized Fuzzy-PID controller is given, and compared with that with only the fuzzy rules optimized in the controller. By simulation tests, it is found that these factors will influence the control performance of the controller, and that they are highly coupled with each other. The more factors for a Fuzzy-PID controller are optimized, the better the solution will be. It can also be inferred from the study that asymmetrical membership functions have more potential in improving a fuzzy controller's performance than symmetrical ones. The multifactor optimization method presented in this paper can in principle also be used to solve other complicated optimization issues.
\end{abstract}

\section{Keywords}

optimization, algorithm, fuzzy, multifactor, genetic, pid, controller

Disciplines

Engineering | Science and Technology Studies

\section{Publication Details}

He, X., Chen, W., Zhu, B., Jiang, Z. \& Cook, C. David. (2012). Multifactor optimization of a Fuzzy-PID controller using genetic algorithm. Advanced Materials Research, 422 268-275. 


\section{Multifactor Optimization of a Fuzzy-PID Controller using Genetic Algorithm}

\author{
Xiaofeng He, Wei Chen, Bihai Zhu* \\ School of Mechanical Science \& Engineering \\ Huazhong University of Science \& Technology \\ Wuhan 430074, China
}

\author{
Zhengyi Jiang, Christopher Cook \\ Faculty of Engineering \\ University of Wollongong \\ Wollongong NSW 2522, Australia
}

\begin{abstract}
The design of a Fuzzy-PID controller involves setting the fuzzy rules, membership functions and its associated scaling factors. How to obtain a better control result and how these scaling factors affect the controller's performance are still challenge. In this paper, the automatic position control system of a Hille 100 experimental rolling mill was taken as a research object. Based on the mathematical control model of the rolling mill, a Fuzzy-PID controller was developed, and the process of implementing global optimization considering all these factors simultaneously by using genetic algorithm was introduced in detail. Through simulation, the performances of the control system with optimized multifactor Fuzzy-PID controller were given, and compared with that with only optimized fuzzy rules controller. By simulation tests, it is found that these factors will influence the control performance of the controller, and they are highly coupled with each other. The more optimized factors for a Fuzzy-PID controller, the more chance to obtain a better solution. It can also be inferred by the study that asymmetrical membership functions have more potential in improving a fuzzy controller's performance than that of symmetrical ones. The multifactor optimization method presented in this paper is verified to be feasible for developing a complex controller and can also be used to solve other complicated optimization issues.
\end{abstract}

Keywords - fuzzy-pid controller; multifactor optimization; genetic algorithm; rolling mill

\section{INTRODUCTION}

Hybrid fuzzy type controllers have been widely used in many industry fields, especially when the controlled objects are complex, nonlinear and time-varying. As an intelligent control strategy, Fuzzy-PID controllers have been widely used in many industrial fields due to it robustness and good adaptability when dealing with time-varying and highly nonlinear problems $[1,2]$. However, the design of a FuzzyPID controller involves many aspects, such as the selection of membership functions and its scaling factors, fuzzy rules, inference mechanism, and the defuzzification strategy [2 - 4], etc. One of the design or tuning methods is relied on expertise knowledge, but it is limited when experts are not available, and also it cannot assure an optimum solution obtained.

So far, genetic algorithms (GA) have been adopted by many researchers to design and optimize fuzzy logic controllers. Homaifar and McCormick designed the membership functions and fuzzy rules of fuzzy controllers simultaneously using GA [4]. In reference [5], GA was used to extract and optimize the rule base of a fuzzy PD controller and also scaling factors of the fuzzy controller were tuned with GA to improve its performance. In authors' previous work [6], the fuzzy rules of a Fuzzy-PID controller for a Hille 100 experimental rolling mill were optimized using GA. In reference [7], both a backward propagation and a genetic algorithm were adopted separately to tune the parameters of the fuzzy tension controller for a tandem rolling mill, including the scaling factors and membership functions for input and output signals, and/or rule weights. These efforts seem to be very successful.

As we know that a Fuzzy-PID controller has some selfadaptability in control process. The question is less or more factors should be optimized when designing a Fuzzy-PID controller and trying to obtain a better control performance. In addition, symmetrical membership functions were adopted for each input or output variable in most of the previous work [1-3, 5-8]. It is not clear if asymmetrical membership functions have more potential in improving the controller's performance.

In this paper, further study is carried out based on the work of reference [6]. The Fuzzy-PID roll gap control system for a Hille 100 experimental rolling mill is taken as a research object. The goal of this study is to find a method to make the control performance of the system more perfect by simultaneously optimizing the controller's fuzzy rules, asymmetrical membership functions and the ranges of the input and output variables, and as well as their influence on the control performance. Implementation of the optimization process using GA is introduced in detail. By simulation, the dynamic performance of the control system, as well as the optimized Fuzzy-PID controller are obtained and compared with the result only optimizing the fuzzy rules. Then the influence of these factors on the control performance is investigated by simulation tests. Finally, some conclusions from this study are given.

\section{REVIEW OF CONTROL SYSTEM FOR HILLE 100 ROLLING MILL}

In Hille 100 experimental rolling mill, two single rod cylinders, which are each controlled by a servo valve, are installed on the driving and operating sides of the mill to adjust the roll gaps. The block diagram of the position control system with a Fuzzy-PID controller can be shown in Fig. $1 . K_{\mathrm{f}}$ is the voltage conversion factor of a displacement 
transducer, $U_{\mathrm{r}}$ is the given voltage signal. The plant model is derived in reference [6], and can be expressed as Eq. (1).
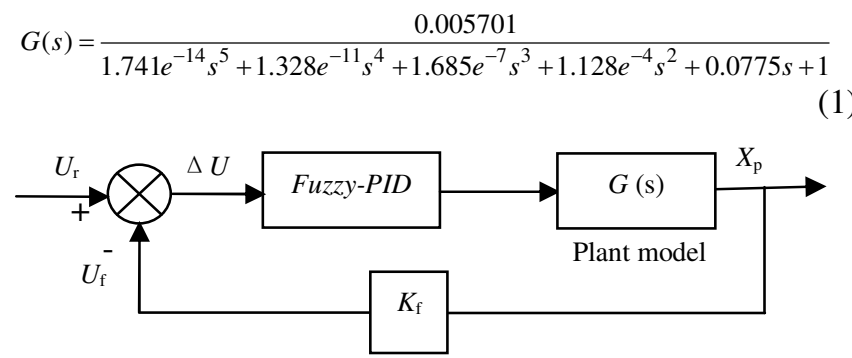

Fig. 1. Block diagram of the AGC system

\section{IMPLEMENTATION OF MULTIFACTOR OPTIMIZATION OF THE FUZZY-PID CONTROLLER}

Genetic algorithm is an effective and parallel method for searching global optimum solution. It is used in this study to optimize the Fuzzy-PID controller while simultaneously considering the fuzzy rules, membership functions and the ranges of the input and output variables. The process of implementing the multifactor optimization is described in the following.

\section{A. Design of the Fuzzy-PID Controller}

The designed Fuzzy-PID controller has two input and three output variables, which are error $e$, change in error ec, proportional gain $k p$, integral gain $k i$ and derivative gain $k d$. The output gains can usually be expressed as Eq. (2) [1].

$$
\left\{\begin{array}{c}
k p=k p_{0}+\Delta k p \\
k i=k i_{0}+\Delta k i \\
k d=k d_{0}+\Delta k d
\end{array}\right.
$$

where $k p_{0}, k i_{0}$ and $k d_{0}$ are the initial values of these gains, which are set to $1.1,20$ and 0.0007 , respectively. $\Delta k p, \Delta k i$ and $\Delta k d$ are the change of the gains based on their initial values, they will be variables in their corresponding ranges and can be determined according to the input error $e$ and change in error $e c$ through fuzzy inference.

Herein, $e \in\left[-e_{\text {range }}, e_{\text {range }}\right], e c \in\left[-e c_{\text {range }}, e c_{\text {range }}\right], \Delta k_{p} \in[-$ $\left.k p_{\text {range }}, k p_{\text {range }}\right], \Delta k i \in\left[-k i_{\text {range }}, k i_{\text {range }}\right]$ and $\Delta k d \in\left[-k d_{\text {range }}\right.$, $\left.k d_{\text {range }}\right]$. To optimize the ranges of the input and output variables, the values of $e_{\text {range }}, e c_{\text {range }}$ and $k p_{\text {range }}, k i_{\text {range }}$, $k d_{\text {range }}$ are expressed as Eqs. (3) and (4), respectively.

$$
\begin{gathered}
\left\{\begin{array}{l}
e_{\text {range }}=n_{1} e_{\text {range } 0} \\
e c_{\text {range }}=n_{2} e c_{\text {range } 0}
\end{array}\right. \\
\left\{\begin{array}{l}
k_{\text {prange }}=n_{3} k_{\text {prange } 0} 0 \\
k_{\text {irange }}=n_{4} k_{\text {irange } 0} \\
k_{\text {d range }}=n_{5} k_{\text {drange } 0}
\end{array}\right.
\end{gathered}
$$

where $e_{\text {range } 0}=1.0, \quad e c_{\text {range } 0}=120, \quad k p_{\text {range } 0}=1.0, \quad k i_{\text {range } 0}=10$, $k d_{\text {range } 0}=0.0009 . n_{1}-n_{5}$ are scaling factors, and they are defined as $n_{1}-n_{5} \in[0.1,2.1]$.

In the Fuzzy-PID controller, each of the input and output variables is assumed to have seven linguistic variables defined as negative big $(N B)$, negative middle $(N M)$, negative small $(N S)$, zero $(Z)$, positive small $(P S)$, positive middle $(P M)$, positive big $(P B)$. Apart from linguistic variable $Z$ which has isosceles triangular-shaped membership function, all others are asymmetric triangularshaped. Constructing a triangular-shaped membership function needs three points of values for each linguistic variable. Taking the input error $e$ as an example, its linguistic variables in this study are defined as

$$
\begin{aligned}
& e \_N B=\left[-e_{\text {range }},-e_{\text {range }}, e \_N B R\right], \\
& e \_N M=\left[e \_N M L,-2 / 3 e_{\text {range }}, e \_N M R\right], \\
& e \_N S=\left[e \_N S L,-1 / 3 e_{\text {range }}, e \_N S R\right], \\
& e \_Z=\left[-e \_Z, 0, e \_Z\right], \\
& e \_P S=\left[e \_P S L, 1 / 3 e_{\text {range }}, e \_P S R\right], \\
& e \_P M=\left[e \_P M L, 2 / 3 e_{\text {range }}, e \_P M R\right], \text { and } \\
& e \_P B=\left[e_{-} P B L, e_{\text {range }}, e_{\text {range }}\right] .
\end{aligned}
$$

where we assume that $e_{-} N B R \in\left(-e_{\text {range }},-1 / 3 e_{\text {range }}\right], e_{-} N M L \in$ $\left[-e_{\text {range }},-2 / 3 e_{\text {range }}\right), e_{-} N M R \in\left(-2 / 3 e_{\text {range }}, 0\right], e_{-} N S L \in\left[-e_{\text {range }},-\right.$ $\left.1 / 3 e_{\text {range }}\right), e_{-} N S R \in\left(-1 / 3 e_{\text {range }}, 1 / 3 e_{\text {range }}\right], e \_Z \in\left(0,1 / 3 e_{\text {range }}\right]$, $e_{-} P S L \in\left[-1 / 3 e_{\text {range }}, 1 / 3 e_{\text {range }}\right), \quad e \_P S R \in\left(1 / 3 e_{\text {range }}, e_{\text {range }}\right]$, $e_{-} P M L \in\left[0,2 / 3 e_{\text {range }}\right), \quad e_{-} P M R \in\left(2 / 3 e_{\text {range }}, e_{\text {range }}\right]$, and $e_{-} P B L \in\left[1 / 3 e_{\text {range }}, e_{\text {range }}\right)$.

The linguistic variables of the other input and output variables are defined as the same method. Thus, there are total 55 parameters which need to be optimized for all the membership functions, and each of them is determined by its ranges defined above and its scaling factor $k(i)$ in Eq. (5).

$$
k(i)=\frac{K}{2^{3}-1}
$$

where $\mathrm{i}=1,2, \ldots, 55 . K \in(0,7)$.

The fuzzy rules of the controller consist of a set of IF-THEN rules as the form

If ( $e$ is $\{\mathrm{NB} \ldots \mathrm{PB})$ and (ec is $\{\mathrm{NB} \ldots \mathrm{PB}\})$,

Then $\left(k_{\mathrm{p}}\right.$ is $\left.\{\mathrm{NB} \ldots \mathrm{PB}\}\right),\left(k_{\mathrm{i}}\right.$ is $\left.\{\mathrm{NB} \ldots \mathrm{PB}\}\right),\left(k_{\mathrm{d}}\right.$ is $\{\mathrm{NB} \ldots \mathrm{PB}\})$.

Therefore, the controller will have 49 rules, each of them contains 3 output linguistic variables corresponding to $k p, k i$ and $k d$.

\section{B. Encoding Method and Initianization}

Because the operated objects are chromosomes in a genetic algorithm, all the optimized parameters should be encoded in a chromosome. In this study, binary encoding method is used for its simplicity.

According to the above design, the fuzzy rules and the membership functions have $147(=49 \times 3)$ and 55 parameters $(K)$, respectively. Each of the parameters will be encoded by a three bit binary number. The scaling factors related to the ranges of the input and output variables can be obtained by Eq. (6) in which $n_{i}$ will be encoded by a six bit binary string. Thus, a chromosome with $636(49 \times 3 \times 3)$ bits represents a possible solution. 


$$
\left\{\begin{array}{l}
n_{i}=\frac{2 n}{2^{6}-1}+0.1 \\
i=1,2,3,4,5
\end{array}\right.
$$

The initial population is set to have 50 chromosomes which are all randomly generated. The maximum generation number is set to 100 . When the iteration number reaches this value, the program will automatically stop. Then the optimum solution can be obtained.

\section{Other Settings}

Other important settings in a genetic algorithm include the fitness function, crossover probability $\left(P_{\mathrm{c}}\right)$ and mutation probability $\left(P_{\mathrm{m}}\right)$. As in reference [6], the inverse value of the integral time absolute error (ITAE) of the system response is used as the fitness function for each chromosome. The ITAE criteria can be obtained by Eq. (7).

$$
\begin{aligned}
& \text { ITAE }=t_{s} \sum_{k=1}^{n}\left(|\alpha e(k)| k t_{s}\right) \\
& \alpha=\left\{\begin{array}{cc}
100 & (e(k)<0) \\
1 & (e(k)>=0)
\end{array}\right. \text {. }
\end{aligned}
$$

where $t_{\mathrm{s}}$ is the sample time, $e(k)$ is the output error in the $k^{\text {th }}$ instance.

The crossover probability $\left(P_{c}\right)$ and mutation probability $\left(P_{m}\right)$ are also defined in reference [6], which are shown in Eqs. (8) and (9), respectively.

$$
\begin{aligned}
& P_{c}=\left\{\begin{array}{cr}
P_{c 1}-\frac{f_{\text {avg }}-f}{f_{\text {avg }}}\left(P_{c 1}-P_{c 2}\right) & \left(f<f_{\text {avg }}\right) \\
P_{c 1} & \left(f>=f_{\text {avg }}\right)
\end{array}\right. \\
& P_{m}=\left\{\begin{array}{cr}
P_{m 1} & \left(f<f_{\text {avg }}\right) \\
\frac{f_{\max }-f}{f_{\max }-f_{\text {avg }}} P_{m 1} & \left(f>=f_{\text {avg }}\right)
\end{array}\right.
\end{aligned}
$$

where $P_{\mathrm{c} 1}$ and $P_{\mathrm{c} 2}$ are the highest and lowest crossover probability, respectively, $P_{\mathrm{c} 1}=0.8, P_{\mathrm{c} 2}=0.5 . P_{\mathrm{m}}$ is the highest mutation probability, $P_{\mathrm{ml}}=0.3 . f_{\max }$ and $f_{\text {avg }}$ denote the maximum and the average fitness of a population, respectively. $f$ is the fitness of a chromosome in a population.

\section{OPTIMIZATION RESULTS}

The control system for the Hille 100 experimental rolling mill shown in Fig. 1 is taken as a research object. The optimization results can be obtained by simulation and are marked with 'MOP_Fuzzy-PID'. For comparison, optimization only aiming at the fuzzy rules of the controller is also carried out and its corresponding results are marked with 'SOP_Fuzzy-PID'. In later case, the scaling factors $n_{1}$ to $n_{5}$ are set to 1.0 , and the membership functions of all the input and output variables are assumed to be isosceles triangular shape with uniform distribution.

The optimized fuzzy rules for SOP_Fuzzy-PID and MOP_Fuzzy-PID are shown in Tables I and II, respectively. The scaling factors of the input and output variables for the two controllers are listed in Table III. The membership functions of $e, e c, k p, k i$ and $k d$ in MOP_FuzzyPID controller are shown in Fig. 2. From the above results, it can be found that either the fuzzy rules or the variables' scaling factors or the membership functions have changed greatly, they seem to vary irregularly. The coupling

\begin{tabular}{|c|c|c|c|c|c|c|c|c|}
\hline \multirow{2}{*}{\multicolumn{2}{|c|}{$K_{\mathrm{p}}, \quad k_{\mathrm{i}}, \quad k_{\mathrm{d}}$}} & \multicolumn{7}{|c|}{ Error } \\
\hline & & $N B$ & $N M$ & $N S$ & $Z$ & $P S$ & $P M$ & $P B$ \\
\hline \multirow{7}{*}{$\begin{array}{l}\text { Change } \\
\text { in Error }\end{array}$} & NB & NM, NB, NB & PM, PS, NB & Z, PS, NM & $\mathrm{NB}, Z, \mathrm{NB}$ & NM, NB, Z & PS, NB, NS & NM, NB, NB \\
\hline & NM & PS, Z, NB & $\mathrm{NB}, \mathrm{PS}, \mathrm{NB}$ & PS, PS, PS & NM, NS, PM & NM, PB, NM & $\mathrm{NS}, \mathrm{PB}, \mathrm{Z}$ & NB, PM, NB \\
\hline & NS & $Z$, NS, NB & PM, NB, NB & PM, NS, NB & PM, NM, PB & NM, NM, PB & $\mathrm{NB}, \mathrm{PB}, \mathrm{PS}$ & NM, PB, PS \\
\hline & 20 & PS, NB, NB & Z, PB, PS & NM, NM, PM & $\mathrm{NM}, \mathrm{NB}, \mathrm{NS}$ & $\mathrm{PB}, \mathrm{NB}, \mathrm{PB}$ & NB, PS, NM & $\mathrm{PB}, \mathrm{Z}, \mathrm{PS}$ \\
\hline & PS & $\mathrm{NB}, \mathrm{PS}, \mathrm{Z}$ & $\mathrm{NB}, \mathrm{PB}, \mathrm{NM}$ & NM, PS, Z & PM, NM, NB & $\mathrm{PB}, \mathrm{Z}, \mathrm{PS}$ & $\mathrm{NM}, Z, \mathrm{NB}$ & $\mathrm{NB}, \mathrm{NB}, \mathrm{PS}$ \\
\hline & PM & $\mathrm{NB}, \mathrm{PS}, \mathrm{Z}$ & NS, PM, NB & NM, NM, PS & PS, NS, PB & NS, PB, NB & NB, PM, PB & $Z, N B, N B$ \\
\hline & $\mathrm{PB}$ & NS, NM, PS & $\mathrm{NM}, \mathrm{NB}, \mathrm{NB}$ & NS, NS, NB & PB, NM, Z & NM, NM, PB & $\mathrm{NB}, \mathrm{NM}, \mathrm{PS}$ & PM, NB, NB \\
\hline
\end{tabular}
relationship among these factors has some uncertainty, therefore manually tuning these factors and finding an

\begin{tabular}{|c|c|c|c|c|c|c|c|c|}
\hline \multirow{2}{*}{\multicolumn{2}{|c|}{$K_{\mathrm{p}}, \quad k_{\mathrm{i}}, \quad k_{\mathrm{d}}$}} & \multicolumn{7}{|c|}{ Error } \\
\hline & & $N B$ & $N M$ & $N S$ & $Z$ & $P S$ & $P M$ & $P B$ \\
\hline \multirow{7}{*}{$\begin{array}{l}\text { Change } \\
\text { in Error }\end{array}$} & NB & $\mathrm{NB}, \mathrm{PB}, \mathrm{PS}$ & NB, PB, PS & PS, NB, PM & $\mathrm{NS}, \mathrm{NB}, \mathrm{PB}$ & $\mathrm{NB}, \mathrm{NS}, \mathrm{NB}$ & PM, NB, NB & PS, NB, NS \\
\hline & NM & $\mathrm{NB}, \mathrm{NB}, \mathrm{Z}$ & NB, PB, NS & NM, PB, NS & PB, NB, NM & NS, NB, PB & NS, PM, NS & $\mathrm{NB}, \mathrm{Z}, \mathrm{NS}$ \\
\hline & NS & PS, PB, NM & $Z, Z, Z$ & PS, Z, NS & $\mathrm{NB}, \mathrm{NS}, \mathrm{PB}$ & PM, NS, Z & $\mathrm{NS}, \mathrm{Z}, \mathrm{NS}$ & NS, NM, Z \\
\hline & $\mathrm{ZO}$ & $\mathrm{PS}, \mathrm{NB}, \mathrm{NB}$ & $Z$, NM, NB & PS, NB, PM & $\mathrm{NM}, \mathrm{Z}, \mathrm{PM}$ & PB, PM, PM & $\mathrm{PB}, \mathrm{PB}, \mathrm{PS}$ & PM, NS, PM \\
\hline & PS & NM, PS, Z & $\mathrm{Z}, \mathrm{PB}, \mathrm{PM}$ & PS, NB, NS & Z, NM, Z & PM, PS, PS & NM, PM, PS & $\mathrm{NB}, \mathrm{NB}, \mathrm{PM}$ \\
\hline & PM & NM, PS, PB & NM, Z, Z & $\mathrm{NB}, \mathrm{NB}, \mathrm{NB}$ & PM, PM, NM & NM, PM, PM & NM, NB, PM & $\mathrm{NB}, \mathrm{NB}, \mathrm{Z}$ \\
\hline & $\overline{\mathrm{PB}}$ & $\mathrm{PB}, \mathrm{PS}, \mathrm{PB}$ & $\mathrm{NB}, \mathrm{NB}, \mathrm{NB}$ & $\mathrm{NB}, \mathrm{NB}, \mathrm{Z}$ & Z, NS, Z & $Z, N S, N B$ & NS, PS, PS & $\mathrm{PB}, \mathrm{NB}, \mathrm{NS}$ \\
\hline
\end{tabular}
optimum solution may become an impossible task.

TABLE I. FUZZY RULES FOR SOP_FUZZY-PID

TABLE II. FUZZY RULES FOR MOP_FUZZY-PID 
TABLE III. SCALING FACTORS OF THE INPUT AND OUTPUT VARIABLES FOR THE TWO OPTIMIZED CONTROLLERS

\begin{tabular}{|c|c|c|c|c|c|}
\hline & $\mathbf{n}_{\mathbf{1}}$ & $\mathbf{n}_{\mathbf{2}}$ & $\mathbf{n}_{\mathbf{3}}$ & $\mathbf{n}_{\mathbf{4}}$ & $\mathbf{n}_{\mathbf{5}}$ \\
\hline SOP_Fuzzy-PID & 1.00 & 1.00 & 1.00 & 1.00 & 1.00 \\
\hline MOP_Fuzzy-PID & 1.50 & 0.64 & 1.81 & 1.47 & 1.56 \\
\hline $\begin{array}{c}\text { MOP_Fuzzy- } \\
\text { PID_SYMM }\end{array}$ & 1.56 & 0.67 & 0.73 & 1.72 & 1.47 \\
\hline
\end{tabular}

The step responses of the control system with the two optimized controllers are shown in Fig. 3 and their main dynamic performances are listed in Table IV. From Table IV and Fig. 3, it can be seen that after multifactor optimization, the settling time is reduced from 0.015 to $0.008 \mathrm{~s}$, overshoot reduced from 4.95 to $-0.056 \%$, and ITAE is reduced from $5.94 \times 10^{-4}$ to $8.0 \times 10^{-5}$, compared with that of the singlefactor optimization. Thus the performance of the control system is significantly improved.
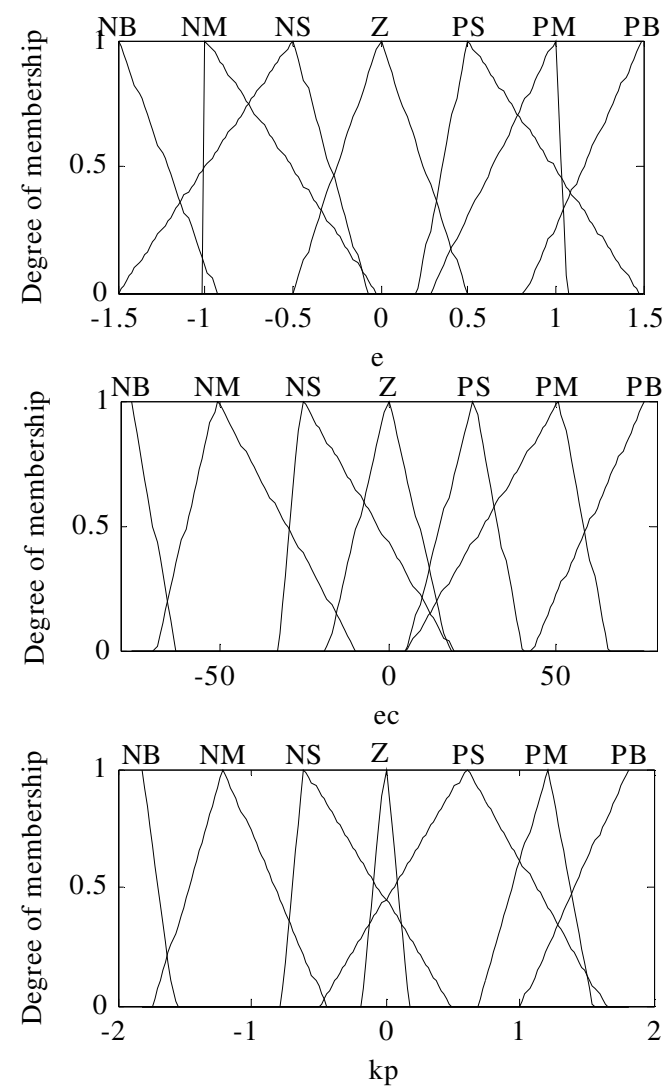
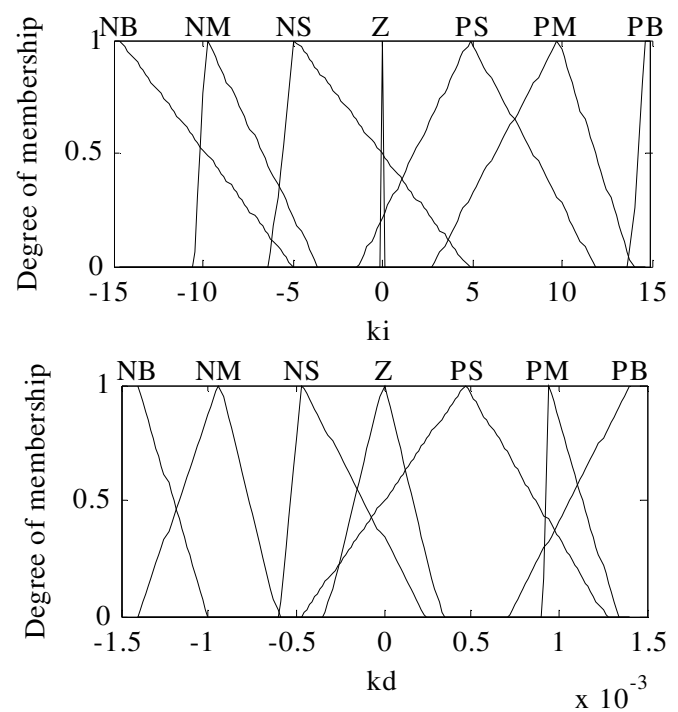

Fig. 2 Membership functions of $e, e c, k p, k i, k d$ in MOP_Fuzzy-PID controller

TABLE IV. DYNAMIC PERFORMANCES WITH THE TWO OPTIMIZED CONTROLLERS

\begin{tabular}{|c|c|c|c|c|}
\hline & $\begin{array}{c}\text { Rise } \\
\text { time (s) }\end{array}$ & $\begin{array}{c}\text { Settling } \\
\text { time (s) }\end{array}$ & $\begin{array}{c}\text { Overshoot } \\
(\%)\end{array}$ & ITAE \\
\hline SOP_Fuzzy-PID & 0.006 & 0.015 & $4.95 \%$ & $5.97 \times 10^{-4}$ \\
\hline MOP_Fuzzy-PID & 0.006 & 0.008 & $-0.056 \%$ & $8.00 \times 10^{-5}$ \\
\hline $\begin{array}{c}\text { MOP_Fuzzy- } \\
\text { PID_SYMM }\end{array}$ & 0.007 & 0.014 & $0.3 \%$ & $2.19 \times 10^{-4}$ \\
\hline
\end{tabular}

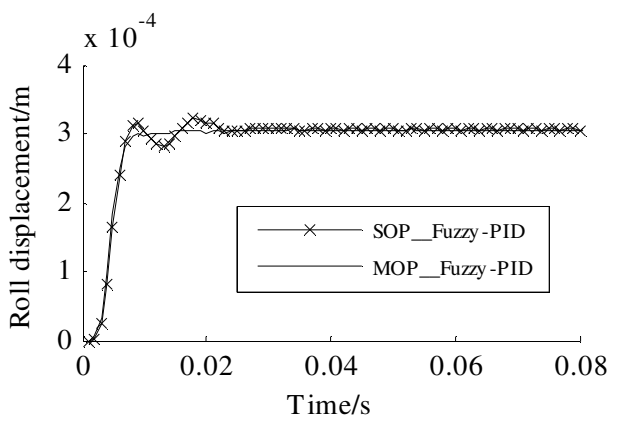

Fig. 3 Step response of the control system with two optimized controllers

\section{INFLUENCE OF SOME FACTORS ON CONTROL PERFORMANCE}

To understand the influence of the above optimized factors on the control performance, some simulation tests were conducted for roll gap setting of the Hille 100 experimental rolling mill.

1) Changing the scaling factors of the input and output variables $\left(n_{1}-n_{5}\right)$ separately. The results show that the dynamic performance will turn to be worse even each scaling factor is slightly changed. 
2) Keeping the optimized scaling factors and fuzzy rules invariable, at the same time all the membership functions are set to be symmetrical triangular shape with uniform distribution, the step response of the control system will change badly, as shown in Fig. 4, in which it is marked with 'MOP_Fuzzy-PID_Modified'.

The above tests illustrate that the many factors in the optimized fuzzy controller are tightly coupled. For this reason, we cannot confirm that a fuzzy controller with asymmetrical membership functions is superior to that with symmetrical ones. Therefore, it is necessary to redesign the fuzzy controller with symmetrical but non-uniformly distributed triangular membership functions and re-optimize the controller from the beginning by the same method. In this case, the optimized results are marked with 'MOP_FuzzyPID_SYMM'. The corresponding scaling factors and dynamic performances are attached to Tables III and IV, respectively for comparison. Its step response is shown in Fig. 5.

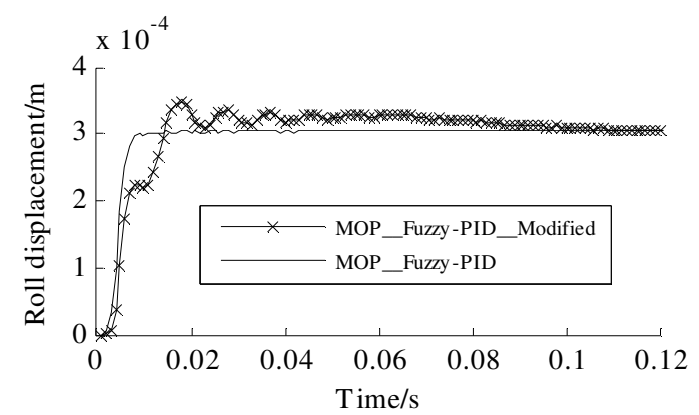

Fig. 4 Step responses of the control system with the optimum controller and its rules modified controller

It is worth noting that in order to avoid occasional results, all the optimization processes in this study were repeated 15 times and recorded. The best one for each situation is taken as the final result.

From Table III, it can be seen that only the scaling factor $n_{3}$ changed a lot and the other changed very little compared with that of 'MOP_Fuzzy-PID'. Table IV and Fig. 5 show that the dynamic performance of the system with MOP_Fuzzy-PID_SYMM controller is better than that with SOP_Fuzzy-PID controller in which only the fuzzy rules are optimized, and is worse than that with MOP_Fuzzy-PID controller in which asymmetrical membership functions are used. The phenomena give us an inspiration that the more the optimized factors for a Fuzzy-PID controller, the more chance to obtain a better solution. It can also be derived from the test results that a fuzzy type of controller with asymmetrical membership functions has better flexibility and adaptability than that with symmetrical ones. Therefore, they will help to improve the controller's performance.

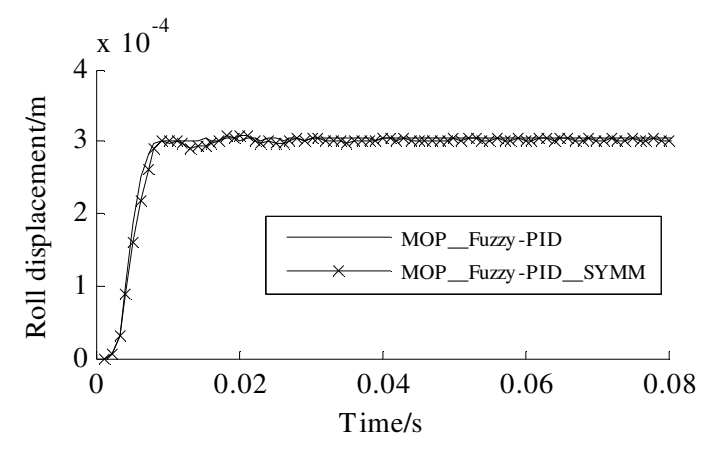

Fig. 5 Step responses of the fuzzy control system with symmetrical and asymmetrical membership functions

\section{CONCLUSION}

From this study, conclusions can be obtained as follows.

1) The fuzzy rules, the membership functions and the ranges of the input and output variables in a Fuzzy-PID controller will influence the controller's control performance. The coupling relationship between these factors is very complex and unclear. When designing a Fuzzy-PID controller, the more the optimized factors, the more chance to find a better solution.

2) Compared with symmetrical membership functions, symmetrical ones have more potential in improving a fuzzy system's control performance.

3) The multifactor optimization method aiming at a Fuzzy-PID controller presented in this study is feasible and can significantly improve the controller's performance. It can also provide an effective solution for the other complex and multifactor optimization issues.

\section{ACKNOWLEDGMENT}

The work was sponsored by the Faculty of Engineering, University of Wollongong and by the Scientific Research Foundation for the Returned Overseas Chinese Scholars, Ministry of Education of China. The authors also appreciated Mr. Liang Luo and Mr. Xianglin Liu for their contributions to the research.

\section{REFERENCES}

[1] X.Y. Xu, Z.W. Bu, Y.L. Cai,,X.Y. Xu, "Fuzzy Logic based Thickness Control System and Its Simulation," The 1st International Conference on Information Science and Engineering (ICISE2009), IEEE Press, Dec. 2009, pp. 37923795, doi: 10.1109/ICISE.2009.612.

[2] P. Tandra, R.P. Nikhil, "SOGARG: A Self-Organized Genetic Algorithm-Based Rule Generation Scheme for Fuzzy Controllers," IEEE Transactions on Evolutionary Computation, IEEE Press, Nov. 2003, pp. 397-415, doi: 10.1109/TEVC.2003.815377.

[3] F. Janabi-Sharifi, "A neuro-fuzzy system for looper tension control in rolling mills," Control Engineering Practice, Vol.13, Jan. 2005, pp. 1-13, doi: 10.1016/j.conengprac.2003.09.013.

[4] A. Homaifar, E. McCormick, "Simultaneous design of membership functions and rule sets for fuzzy controllers using genetic algorithms," IEEE Trans. Fuzzy Syst., Vol. 3, 1995, pp. 129-139. 
[5] M.S. Alam, M.O. Tokhi, "Hybrid fuzzy logic control with genetic optimization for a single-link flexible manipulator," Engineering Applications of Artificial Intelligence, Vol. 21, 2008, pp. 858-873.

[6] X.F. He, L. Luo, B. Zhu, Z.Y. Jiang, C. Cook, "Optimization of the Fuzzy-PID Controller for a Hille 100 Experimental Rolling Mill based on a Genetic Algorithm," 2011 International Conference on Computers, Communications, Control and Automation (CCCA 2011), IEEE Press, Feb. 2011, pp. 258-263
[7] F. Janabi-Sharifi, J. Liu, "Design of a Self-Adaptive Fuzzy Tension Controller for Tandem Rolling," IEEE Transactions On Industrial Electronics, vol. 52, Oct. 2005, pp. 1428-1438, doi: 10.1109/TIE.2005.855653.

[8] H. Zhang, B. Zhang, F. Wang, "Automatic Fuzzy Rules Generation Using Fuzzy Genetic Algorithm," Proceedings of the Sixth International Conference on Fuzzy Systems and Knowledge Discovery, IEEE Press, Aug. 2009, pp. 107-112, DOI 10.1109/FSKD.2009.420 